\title{
Agriculture Triggered Drought is Causing Desertification
}

ISSN: 2637-7659

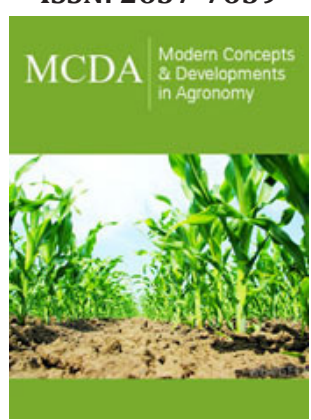

*Corresponding author: Debankur Sanyal, Department of Agronomy, Horticulture and Plant Science, South Dakota State University, Brookings SD 57007, USA

Submission: 眥 June 07, 2021

Published: 眥June 16, 2021

Volume 8 - Issue 5

How to cite this article: Johnathon Wolthuizen, Debankur Sanyal. Agriculture Triggered Drought is Causing Desertification. Mod Concep Dev Agrono. 8(5). MCDA. 000699. 2021. DOI: 10.31031/MCDA.2021.08.000699

Copyright@ Debankur Sanyal. This article is distributed under the terms of the Creative Commons Attribution 4.0 International License, which permits unrestricted use and redistribution provided that the original author and source are credited.
Johnathon Wolthuizen and Debankur Sanyal*

Department of Agronomy, Horticulture and Plant Science, South Dakota State University, USA

\section{Abstract}

Desertification is a major concern for humankind as global population continues to grow. While agriculture provides food to billions of people on earth, inefficient management of natural resources during agricultural practice increases frequency of droughts in the drier climatic regions on earth. Repeated droughts triggered by agricultural practices is causing desertification.

Keywords: Desertification; Agriculture; Drought

\section{Introduction}

Desertification is the land degradation process that forms deserts in the arid, semiarid, and dry subhumid climates due to climatic variation and anthropogenic activities [1]. This takes place slowly over time, typically from a loss of nutrients from a landscape coupled with frequent, and long-lasting drought. Desertification impacts the lives of one-fifth of world population, most of which are poor [2,3]. The Sahara Desert covers an area of $\sim 9$ million km2 across North Africa, extending from $\sim 12^{\circ} \mathrm{N}$ to $\sim 34^{\circ} \mathrm{N}$, making it the largest non-polar desert in the world [4,5]. From 1920 to 2018 the Sahara Desert grew by around 10\% [6], a growth of over 90 million hectares and a growth rate of more than 900,000 hectares a year. But why is the Sahara Desert growing? Why are there are so many reports of increasing desertification around the globe? There are many theories as to why, and many are probably at least partially right. Factors such as naturally changing ocean temperatures, increasing agricultural land, and human caused global warming. Whatever the cause for the growth of the Sahara is it is resulting in one thing for neighboring areas, desertification [7].

The Great Plains of central North America is an area historically known for droughts, often severe and sometimes lasting for years on end $[8,9]$. Even with the long record of historical droughts the Great Plains has been an area of expansive agriculture development for over 150 years. This development of agriculture is due in large part to fertile, deep topsoil across the plains and great growing conditions, at least when precipitation is adequate. Even though this area is known for its droughts naturally occurring, it is believed that some droughts are triggered by agriculture, or at least amplified by it [10]. This reasoning is simple: before the great plains were settled there was a vast sea of grass that stretched for hundreds of miles broken up by the occasional rivers lined with massive stands of trees. In modern times trees can be hard to come across in the great plains and most of the warm season tall grass that historically had a home here can no longer be found. In their place you have fence lines and corn fields. Barbed wire fences don't work as well for wind protection as a thick forest of trees does, and tilled corn residue doesn't offer much protection from the wind, sun, or rain to the fertile soil underneath. Bare soil heats up heats up much faster than covered soils [11], this increase in temperature also causes a decrease in soil moisture. In years that are extremely dry but not quiet in a drought, having large areas of exposed soil can trigger a drought by simply 
being hotter and drier. Thermal updrafts are localized heating of air causing air to rise over a specific area [12]. This phenomenon can be found in nature near mountainous areas with large amounts of exposed rock, but they can also be found over cities with their large amounts of dark metal and concrete. These thermal updrafts have the ability to prevent small storm systems from forming over an area or even passing over an area because small systems cannot overcome the vertical push the updraft causes. These updrafts can also be found over areas experiencing drought, or even a dry year.

What does all this mean? It means if a region has an abnormally dry fall and winter but is not necessarily in a drought as of yet. If that region has something that can trigger these thermal updrafts, a drought could be triggered. There can be a lot of factors affecting this, but in the agricultural context what we usually see is that with dry falls or winters, many farmers will be able to successfully till their fields relatively early in the spring, if all the fields over an area are tilled this will expose the entire region to not only increased soil temperatures but also decreased soil moisture, and increased surface air temperatures. As the farmers come through to plant their crops into their warmer, drier soil, there is more likelihood that the crops will fail, leaving their soil exposed later into the growing season when temperatures really begin to climb, and the dryness and temperatures of their soils really begin to become apparent. If high winds come across the area, they could take up the soil damaged through tillage and lay it in an area that has good moisture, but now it is covered in a dark layer of fast heating soil resulting in a depletion of soil moisture in a new area. As the season goes on, this region will start to move small storms away because of the heat. Bigger storms will still be able to come through, but they are often powerful to produce large amounts of precipitation in short periods of time resulting in high amounts of runoff and low amounts of soil infiltration. These large storms can do relatively nothing for struggling crops. As the year progresses the size of the storm that can pass over the area increases and the potential for precipitation decreases. The results in a regional drought.

During regional droughts there is often heavy amounts of soil erosion caused by wind. This is because failed crops provide little to no protection from the wind and with little soil moisture there is nothing to hold the soil in place allowing it to blow freely. This wind erosion is a very real and very visible cause of soil degradation over a region and our treatment of the landscape is a very real cause for regional drought formation. As stated above, desertification is not a sudden event but one that take centuries to occur, but once it does it is extremely difficult to stop the spread. Our agricultural practices are leading to the desertification of our most productive areas, and it is something we can fix by changing the way we produce food. Options like no till can reduce soil temperatures and increase soil moisture. Cover crops increase a soils ability to stay in place with wind and rain events. Perennial crops require less working of the soil and provide more living roots and year-round protection from the environment. This is not something that one lone producer can achieve on their own, it needs to be a region wide, a nationwide, and a worldwide cause to change this, because one lone producer in a region of human caused drought is still in that drought, but if we can prevent the drought in the first place, we can stop the desertification of our agricultural lands.

\section{References}

1. Mirzabaev A, Wu J, Evans J, Garcia Oliva F, Hussein IAG, et al. (2019) Desertification.

2. Fleskens L, Stringer LC (2014) Land management and policy responses to mitigate desertification and land degradation. Land Degradation and Development 25(1): 1-4.

3. UNCCD (1994) United Nations convention to combat desertification in countries experiencing serious drought and/or desertification, particularly in Africa. Paris: United Nations Convention to Combat Desertification, UNCCD, Bonn, Germany.

4. Liu Y, Xue Y (2020) Expansion of the Sahara Desert and shrinking of frozen land of the Arctic. Scientific reports 10(1):1-9.

5. Pastore G, Baird T, Vermeesch P, Resentini A, Garzanti E (2021) Provenance and recycling of Sahara Desert sand. Earth-Science Reviews 216: 103606.

6. Thomas N, Nigam S (2018) Twentieth-century climate change over Africa: Seasonal hydroclimate trends and sahara desert expansion. Journal of Climate 31(9): 3349-3370.

7. Kassas M (1995) Desertification: a general review. Journal of Arid Environments 30(2): 115-128.

8. Hu Q, Torres Alavez JA, Van Den Broeke MS (2018) Land-cover change and the "Dust Bowl" drought in the US Great Plains. Journal of Climate 31(12): 4657-4667.

9. Laird KR, Fritz SC, Maasch KA, Cumming BF (1996) Greater drought intensity and frequency before AD 1200 in the Northern Great Plains, USA. Nature 384(6609): 552-554.

10. Gerken T, Bromley GT, Ruddell BL, Williams S, Stoy PC (2018) Convective suppression before and during the United States Northern Great Plains flash drought of 2017. Hydrology and Earth System Sciences 22(8): 4155-4163.

11. Enz JW, Brun LJ, Larsen JK (1988) Evaporation and energy balance for bare and stubble covered soil. Agricultural and Forest Meteorology 43(1): 59-70.

12. Li Y, Xu H, Liu D (2011) Features of the extremely severe drought in the east of Southwest China and anomalies of atmospheric circulation in summer 2006. Acta Meteorologica Sinica 25(2): 176-187. 